\title{
Comparative Assessment of Hydroponic and Geoponic Cultivation Systems for Sustainable Spinach Cultivation
}

\section{Ain-ul-Abad Syed ${ }^{1 *}$, Zaheer Ahmed Khan ${ }^{1}$, Shakeel Hussain Chattha ${ }^{1}$, Irfan Ahmed Shaikh ${ }^{2}$, Mian Noor Hussain Asghar Ali ${ }^{1}$, Zohaib ur Rehman Bughio ${ }^{3}$, Shahzad Hussain Dahri ${ }^{2}$ and Ghous Bakhsh Buriro ${ }^{4}$}

${ }^{1}$ Department of Farm Structures, Faculty of Agricultural Engineering, Sindh Agriculture University Tandojam 70060, Pakistan; ${ }^{2}$ Department of Irrigation and Drainage, Faculty of Agricultural Engineering, Sindh Agriculture University Tandojam 70060, Pakistan; ${ }^{3}$ Department of Soil Sciences, Faculty of Crop Production, Sindh Agriculture University Tandojam 70060, Pakistan; ${ }^{4}$ Department of Hydrology and Water Resource Engineering, School of Water Resources and Hydropower Engineering, Wuban University China 430072.

Abstract | This study aims to solve water constraints in today's agricultural industry, as well as decreasing soil conditions and growing food demand. The primary goal of current research is to find a substitute for conventional farming practices that could conserve water, fertilizer and generate more sustainable food vertically and horizontally. Two treatments were performed, each with two replications. The treatments included hydroponic (soil-less) and geoponic (soil) spinach seed cultivation. The seed was initially grown in a seedling tray before being transferred onto a prepared plot and a hydroponic model, respectively. All the standard materials (made of plastic) needed for a perfect low-cost hydroponic model, obtained from local markets, were combined accordingly to achieve the results of set goals. A total of $9680.00 \mathrm{PKR}$ was the approximate expense of the manually manufactured hydroponic model. The field under geoponic cultivation was maintained equal to the manufactured hydroponic model (4'x 4'). Full-Spectrum Light-emitting diode (LED) grow light was used to meet the plants' light requirements. The stock solution (a combination of water and nutrients) was used to feed the transplanted plants during hydroponic cultivation. On average, relative to water use under geoponic agriculture, the hydroponic model's productivity was 97.42 percent. The growth efficiency of the hydroponic spinach crop was much higher than that of geoponic cultivation. On average, the leaf area was 24 percent, height 25 percent, and steam scale 24 percent greater than geoponic. Statistically, there was a substantial $(\mathrm{p}<0.05)$ variation in the leaf area, height, and steam scale of plants, suggesting that hydroponic technology could also increase crop yields by up to 25 percent. It is inferred from this analysis that hydroponic cultivation is successful in saving water and fertilizer and increasing crop yields at the desirable limit. To enhance yield, the hydroponic model should be equipped with sensors and artificial intelligence technologies to handle difficulties related with food supplies. The hydroponic growing technology should be introduced to cities. At the time, such as when challenged with Covid-19 and the locust attack.

Received | April 19, 2021; Accepted | July 26, 2021; Published | August 14, 2021

*Correspondence | Ain-ul-Abad Syed, Department of Farm Structures, Faculty of Agricultural Engineering, Sindh Agriculture University Tandojam 70060, Pakistan; Email: ainulibadsyed@gmail.com

Citation | Syed, A.A., Z.A. Khan, S.H. Chattha, I.A. Shaikh, M.N.H.A. Ali, Z.R. Bughio, S.H. Dahri and G.B. Buriro. 2021. Comparative assessment of hydroponic and geoponic cultivation systems for sustainable Spinach cultivation. Pakistan Journal of Agricultural Research, 34(4): 678-688.

DOI | https://dx.doi.org/10.17582/journal.pjar/2021/34.4.678.688

Keywords | Full spectrum grow light, Hydroponics, Spinach, Soilless cultivation, Water saving efficiency 
Introduction

$\mathrm{P}$ akistan is an agriculture enriched country whose $42.3 \%$ of the labor force is waged directly from the agriculture sector (GoP, 2019), contributing to an 18.9\% share of Pakistan's Gross Domestic Product (GDP). This production is gained from cultivated land of $28.05 \%$ of the overall country land (GoP, 2014). A productive agriculture farm requires a good source of water of the total national waterways available, which are 160 million acre-feet (MAF). Merely 56 MAF arrives at the farm level. In contrast, the other portion of the water is wasted each year, during the rainy season or by improper irrigation practices, runoff, and joining the sea at the time of the flood. It has been stated that in the period from 1995 to 2020 , water availability for agriculture is projected to decrease between $72 \%$ to $62 \%$, and globally, a decrease from $87 \%$ to $73 \%$ in developing countries has also been predicted (Khan et al., 2006). Contributing to the problem, Pakistan is facing alarming population growth, mostly in urban areas (GoP, 2014). Due to which Pakistan stands at the position of $6^{\text {th }}$ populated country globally (United Nations, 2014); with the increasing population, the food demand increases. On the other hand, global warming is also contributing to the degradation of the resources, causing seasonal fluctuations in temperature that reduce production and yield insufficient crop production (Arifullah et al., 2009). Pakistan is working to advance its agricultural technology and innovation on different new methods of farming (MNFSR, 2012).

Spinach (Spinacia oleracea) is widely grown all over Pakistan due to its short growing cycle and high nutritional value. It is consumed in every household; however, many studies have proved that this leafy vegetable houses a higher level of micronutrients (Steyn et al., 2001; Bhatti et al., 2021). The consumption of spinach depends upon the consumer. Mostly in western countries, the raw form is used in salads, but in South Asia, this leafy plant is cooked into different curries. It offers a considerable quantity of vitamins such as B6, folate, riboflavin, dietary fiber (soluble), minerals, and omega-3 fatty acids (Ferreira et al., 2018; Muchate et al., 2019). Spinach is also an iron deficiency supplement plant for vegetarians (Oulai et al., 2014). In recent years, soilless technology, particularly hydroponic culture, has produced reliable and healthier vegetables. Soilless culture becomes prominent in encouraging clean edible green leafy vegetables and serving them for consumption with minimum processing (Nicola et al., 2007).

Hydroponic is a method to alternate the plants' growing medium to a non-soil or soilless process in areas such as urbanized cities or regions with water scarcity and water stress. This method comes with two types of systems, one of them is non-circulating, and the other one is circulating, which enhances selection and matches the plant requirement accordingly. Any such soilless model is consisting of these central components, quality water, nutrient solution, adequate dissolved oxygen level, storage tank, pumps, net cups, and growing medium. Different kinds of growing mediums are used in Hydroponics, mentioned as supporting media, potting media, aggregate systems, and substrate (Gruda, 2009). Soilless cultivation is free of any climate change. Though, it can grow any crop year-round, which enhances its economy in offseason production (Manzocco et al., 2011; Malik et al., 2018). The present concern in geoponic cultivation is the water quality, which is declining fast because of the irregular use of chemicals causing groundwater contamination during the farming cycle, making water an essential commodity for future growers and their related industries (Hawkes, 2014). Hydroponics preserve a significant amount of water as irrigation is not needed and waterlogging rarely happens. The advantage of this method over traditional cultivation is that it eliminates some conventional agricultural activities, such as weeding, spraying, irrigation, and tilling (Jovicich et al., 2003). When there is no freshwater present in the underground aquifer, relatively nonusable water is present; that water can also be treated and used in this agricultural technique. The water used in this procedure is either distilled or desalinized and readily offered after treatment in the coastal sites, cites with a lack of fresh-water, and areas with degraded water quality. For the region where environmental stress (cold, heat, dessert) is a real concern, this technique is particularly useful (Polycarpou et al., 2005). This enables the ability to grow vegetation in such a place with the potential of the highest yield. In terms of water, fertilizer saving, and low-labour requirements (Jovicich et al., 2003), hydroponic technology is very efficient (90\%); perhaps it would yield more than conventional agriculture on a limited amount of land and water (Waqas et al., 2021). Given this highly productive farming technology and the facts stated above, the objective of the study was to conduct research on the effectiveness 
of Hydroponics model on the growth rate and water usage efficiency under spinach crops cultivation.

\section{Materials and Methods}

\section{Experimental design}

Reservoir: The reservoir is a significant component that stores the success ingredients of the system. That was designed according to the Deep-Water Culture model; a standard is comprised of styrofoam raft at the top which holds net cups and aeration stone at the bottom for providing oxygen to the stock solution (Resh, 2013; Janeczko and Timmons, 2019), having dimensions as $13.5 " \times 8.25 " \times 8.3$ " shown in Figure 1 . Distilled water was filled in the tank, after which a combination of nutrients was mixed into it. The quantity of filled water was first measured so that the gap between net pots and water remains optimum. A porous air stone was positioned at the bottom of the tank stuck with silicon, which receives air from the pump, dissolving oxygen into the stock solution. It also provides sufficient oxygen and nutrient concentrations, testing electrical conductivity, total dissolved salts, and $\mathrm{pH}$ (Domingues et al., 2012). Another necessary aspect of this system is to cover it with aluminum foil. Foil reduces the sudden temperature changes, and the growth of microorganisms like algae and molds multiply rapidly in the tank due to presence of light.

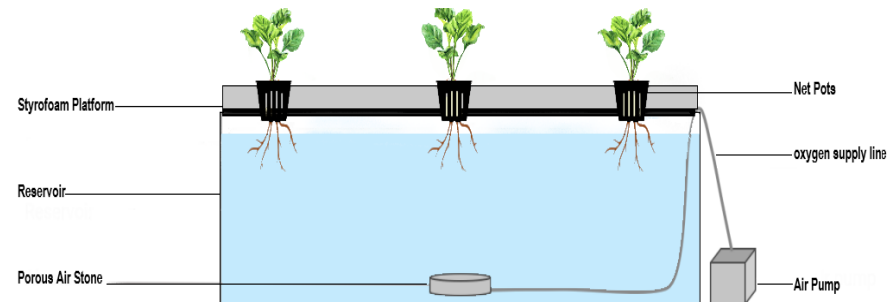

Figure 1: Deep water culture reservoir system (used bydroponic model).

The volume of the reservoir before and after placement of net pots was determined using the relationship 1 to 2.

$$
\begin{aligned}
& V 1=L \times H_{1} \times W \ldots(1) \\
& V 2=L \times H_{2} \times W \ldots(2)
\end{aligned}
$$

Where;

$\mathrm{W}=$ Width of the reservoir; $\mathrm{L}=$ Length of the reservoir; H1= Height of reservoir; V1= Volume of Reservoir; V2 = Volume of Reservoir after Placement of Cups; H2= Height of Reservoir after Placement of Cups.
Net pots: Net pots are pots that are specially designed for Hydroponics; they are also called the net cups. At the bottom, they have a meshy space from where roots travel into the stock solution to nurture and grow a plant. Expendable clay pellets are filled inside net pots to hold the plants (Szilágyi et al., 2006), shown in Figure 2. Another benefit of the mesh structure is to circulate air through the bottom of the cup to the root zone. The Styrofoam platform was cut into an optimum size with three holes in it where the net pots 4-inch (diameter) were inserted (Ako and Baker, 2009). The walls of the reservoir support the whole platform.

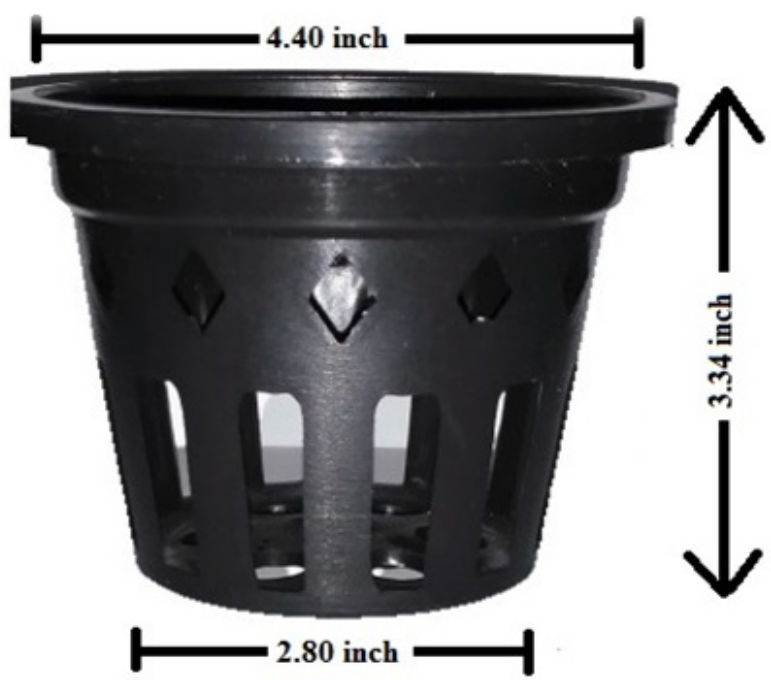

Figure 2: Net pots used in the study.

Oxygen supply: The oxygen level is an essential parameter in Hydroponics; that is why welloxygenated and nutrient-enriched water is used rather than soil (Huttner and Bar-zvi, 2003; Suhardiyanto et al., 2009). An air pump supplies the oxygen in water with the help of a porous air stone connected with a silicon pipe with a pump; the air pump is shown in Figure 3. This oxygen is called Dissolved oxygen (D.O). Oxygen is so essential that in the water, without it the plant starts suffocating, which causes the failure of the system. Proper distribution of oxygen enhances root growth and their formation, increasing the shoot and root size by a right margin (Suyantohadi et al., 2010).

Grow light: Sunlight is necessary for each plant or crop to fulfill its growth requirements. The lack of sunshine or radiation affects the photosynthesis process, and plants end up dying. In a hydroponic system, grow light is used to tackle this condition. Full-Spectrum Light-emitting diode (LED) with 
IP65 waterproofing (Figure 4) makes it an ideal light for the deep water culture method (Maneejantra et al., 2016). This light was mounted on plastic pipes stand, making it light-weight and durable. A timer system was used to monitor the length of LED light, which is usually 18 hours during the early growth period, 16 hours in the middle stage, and 12 hours when the plant has matured and flourishing.

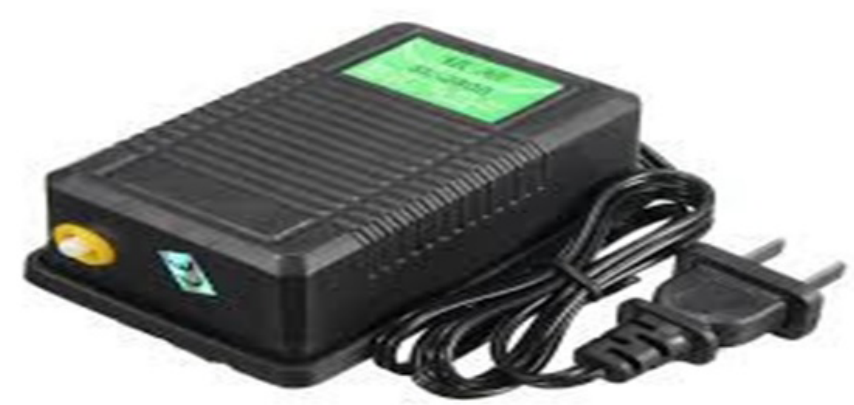

Figure 3: Air pump used in deep water culture model.

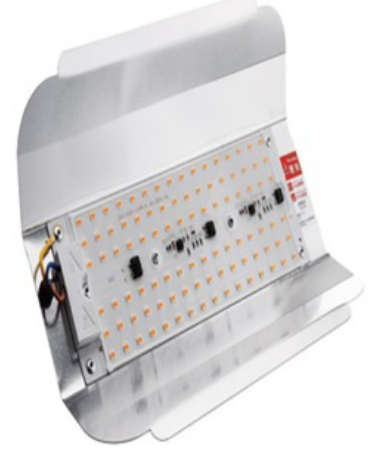

Full-Spectrum LED Grow Light

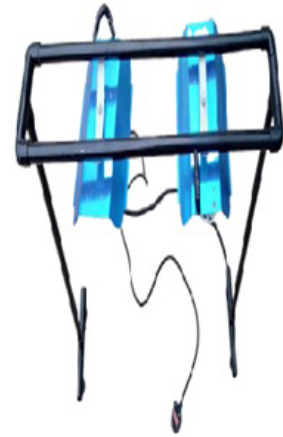

PVC LED Light Mount
Figure 4: Full-spectrum light-emitting diode and PVC pipes light stand.

\section{Cultivating conditions}

This study was performed at the Department Laboratory of farm structures, faculty of Agricultural Engineering, during the September to November of 2019. Spinach (Spinacia oleracea) seeds were bought from an online seed store (MTS Gardening). Seeds were sown in a foldable plastic germination tray (Öztekin et al., 2018). In the seedling tray, Coco coir was used as a growing medium, washed with distilled water several times before using it. After this, seeds were sown and put under full-spectrum light till seedlings become mature and transplanted into the hydroponic system. This entire research was concluded in six weeks.

\section{Physiochemical properties of the nutrient solution}

The maintenance of parameters is essential for proper plant development. The ambient Temperature and specific water properties, including electrical conductivity (EC), total dissolved solids (TDS), potential hydrogen $(\mathrm{pH})$, water temperature, and water quantity, have been reported. All parameters were verified at an interval of 3 days.

\section{Plant growth analysis}

Development parameters include the leaf area, height, and stem size at the end of the experiment of randomly selected spinach crops grown under both treatments (Biemond et al., 1996). The plant leaf area was measured with a planimeter (Trimble, 2019), the plant height was measured with a measuring tape, and the plant stem size was measured with a Vernier caliper. The findings obtained under treatments were compared with each other for a proper evaluation of the disparity in spinach growth and yield.

\section{Water quality}

In the hydroponic model, purified water (Distilled) with EC $24 \mu \mathrm{S} / \mathrm{cm}$, TDS $12 \mathrm{ppm}$, and $7.0 \mathrm{pH}$ was used. However, irrigation water with EC $2760 \mu \mathrm{S} /$ $\mathrm{cm}, 1329 \mathrm{ppm}$, and $7.1 \mathrm{pH}$ were used for the geoponic (standard) culture of spinach crops.

\section{Comparison of bydroponic model}

To evaluate the designed soilless cultivation model, conventional spinach crop cultivation was performed in the field at the Sindh Agriculture University Colony, where all the necessary parameters were calculated accordingly. Land calculations were also made for water usage, chemical fertilizer, and other required parameters. As discussed above, both the hydroponic and traditional cultures of cultivation of the spinach crop were conducted accordingly to compare the replication of the conventional spinach cultivated in the plot of around $16 \mathrm{ft}^{2}$ with the replications of hydroponic treatment.

$$
\text { No of treatments }=\text { Two }\left(T_{1} \text { and } T_{2}\right)
$$

T1= Deep Water Culture (Hydroponics) cultivation of spinach; $\mathrm{T}_{2}=$ Traditional (Geoponic) cultivation of spinach.

\section{Cost of hydroponic model}

The materials required for the Hydroponic Model design were first assessed, and the overall cost was estimated. Table 2 shows the unit and total cost of materials used in the model's assembly and design by multiplying each component by its unit rate and 
adding them together (Wang et al., 2013). It may be written mathematically as:

$$
T C=\sum_{i=1}^{n}(M i) \cdot(U C i)
$$

Where;

$\mathrm{i}=$ represent number of material used in fabrication; $\mathrm{TC}=$ total cost of material; $\mathrm{UC}=$ unit cost of material; $\mathrm{M}=$ material used to fabricate model.

\section{Statistical analysis}

The data was evaluated statistically through the computer program SPSS 19. The mean contrast Least Significant Difference (LSD) value of significant differences was determined at a probability of $\leq 0.05$.

\section{Results and Discussion}

\section{Manually fabricated and designed model}

This model was designed following the availability of the materials in the local market and their cost, as shown in Figures 5 and 6.
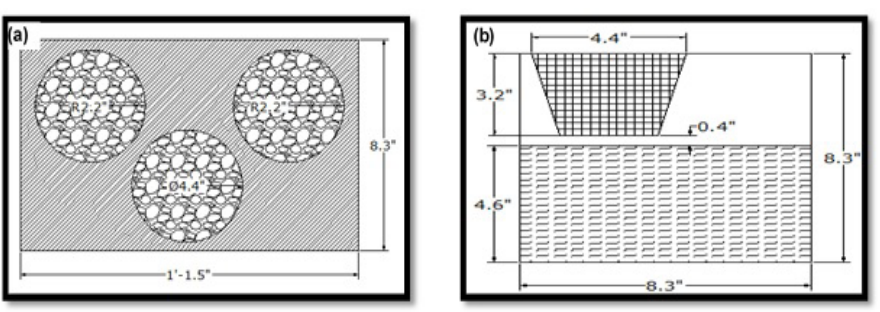

Figure 5: Schematic (a) top view and (b) side view of the hydroponic model (Dimensional view).

\section{Climate conditions}

The temperature in hydroponics is an essential aspect that cannot be neglected if a proper system is to be designed. The productive system must be in a specific range because temperature directly affects the $\mathrm{pH}$ value of the stock solution. When the value is disturbed, it affects nutrient uptake in plants, causing growth difficulties in the rootzone, stem width, leaf quality and quantity and also could cause plant hypoxia. The difference in relative humidity and temperature evidence from indoor and outdoor sites indicates that, compared to conventional agriculture, the indoor hydroponic system was more effective in temperature variations varying from $27.6^{\circ} \mathrm{C}$ to $29.4^{\circ} \mathrm{C}$ (Table 1 ); whereas, the ambient temperature variation of traditional spinach cultivation ranged from $29.5^{\circ} \mathrm{C}$ to $37.1{ }^{\circ} \mathrm{C}$ (Table 1). Such a hydroponic climate control house could achieve any optimum temperature that matches the plant requirement, placing hydroponic above the conventional system.

\section{Cost estimation}

A well-designed soilless system eliminates water and fertilizer loss by up to $90 \%$. Compared to the traditional approach, the experimental hydroponic model developed using the materials mentioned above was found to be successful in terms of its design, spinach crop growth, working parameters, and performance. Table 2 displays the unit and the approximate cost of the components used to make and build the product. Table 2 reveals that PKR 9680.00 is the average cost for a single unit, although the initial cost of production and construction is high relative to the conventional cost. The material bought for this model, though, is mainly sturdy plastic, making it reusable again. These rigid types of plastic stuff would last long and work for a reasonable period. The seed is the only thing that would be needed for the next crop cycle, and the cost of the seed would not escalate from PKR 100.00, which is much cheaper and better compared to conventional spinach cultivation. Hence this estimation suggests that the larger the model, the higher would be its production and earning.

Table 1: Temperature and relative humidity under hydroponic and traditional cultivation of Spinach.

\begin{tabular}{llllllll} 
S. No & $\begin{array}{l}\text { Reservoir } 1 \text { Inside } \\
\text { Temp: }\left({ }^{\circ} \mathbf{C}\right)\end{array}$ & $\begin{array}{l}\text { Reservoir 2 In- } \\
\text { side Temp: }\left({ }^{\circ} \mathbf{C}\right)\end{array}$ & $\begin{array}{l}\text { Indoor outside } \\
\text { Temp: }\left({ }^{\circ} \mathbf{C}\right)\end{array}$ & $\begin{array}{l}\text { Indoor } \\
\text { R.H (\%) }\end{array}$ & $\begin{array}{l}\text { Traditional Ambi- } \\
\text { ent Temp: }\left({ }^{\circ} \mathbf{C}\right)\end{array}$ & $\begin{array}{l}\text { Outdoor } \\
\text { R.H (\%) }\end{array}$ & $\begin{array}{l}\text { Growth Dura- } \\
\text { tion (Days) }\end{array}$ \\
1 & 28.00 & 28.1 & 28.7 & 50 & 37.0 & 56.0 & $1^{\text {st }}$ \\
2 & 28.90 & 28.8 & 29.4 & 44 & 33.0 & 61.0 & $3^{\text {rd }}$ \\
3 & 28.60 & 28.4 & 28.3 & 69 & 34.0 & 69.0 & $6^{\text {th }}$ \\
4 & 28.40 & 28.4 & 27.6 & 56 & 33.0 & 67.0 & $9^{\text {th }}$ \\
5 & 29.10 & 30.4 & 29.4 & 40 & 31.0 & 60.0 & $12^{\text {th }}$ \\
6 & 30.00 & 30.2 & 28.8 & 47 & 31.0 & 60.0 & $15^{\text {th }}$ \\
7 & 28.20 & 28.4 & 29.1 & 40 & 29.5 & 54.0 & $18^{\text {th }}$ \\
8 & 28.10 & 28.1 & 28.7 & 49 & 30.0 & 56.0 & $21^{\text {st }}$ \\
\hline
\end{tabular}


Table 2: Cost of materials used in hydroponic model.

$\begin{array}{lllll}\text { S. No } & \text { Material/Item Name } & \text { Price per unit (PKR) } & \text { Quantity } & \text { Total price (PKR) } \\ 01 & \text { Air Pump } & 450.00 & 01 & 450.00 \\ 02 & \text { Air Stone } & 100.00 & 01 & 100.00 \\ 03 & \text { TDS and EC Meter } & 1100.00 & 01 & 1100.00 \\ 04 & \text { pH Meter } & 1000.00 & 01 & 1000.00 \\ 05 & \text { Digital temperature and humidity meter } & 850.00 & 01 & 850.00 \\ 06 & \text { Net Cup } & 50.00 & 03 & 150.00 \\ 07 & \text { Styrofoam Sheet } & 80.00 & 01 & 80.00 \\ 08 & \text { Plastic Reservoir } & 400.00 & 01 & 400.00 \\ 09 & \text { Hydroponic flora grow, bloom micro }(120 \mathrm{ml}) & 1000.00 & 01 & 1000.00 \\ 10 & \text { Full-Spectrum LED Grow Light }(100 \mathrm{~W}) & 1500.00 & 01 & 1500.00 \\ 11 & \text { Digital Timer Device } & 1650.00 & 01 & 1650.00 \\ 12 & \text { Coco Peat } & 100.00 & 01 & 100.00 \\ 13 & \text { Clay Pebbles } & 200.00 & 01 & 200.00 \\ 14 & \text { Seedling Tray } & 150.00 & 02 & 300.00 \\ 15 & \text { Aluminium Foil } & 250.00 & 01 & 250.00 \\ 16 & \text { Silicone Air and Water Tube } & 100.00 & 01 & 100.00 \\ 17 & \text { PVC LED Light Mount } & 450.00 & 01 & 450.00 \\ \text { Total price for hydroponic unit } & & & 9,680.00\end{array}$
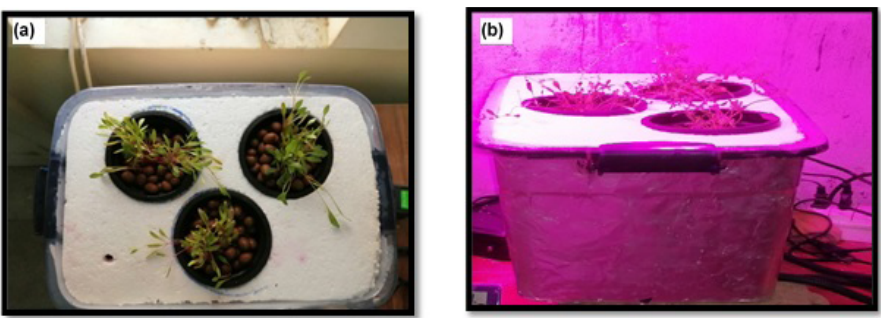

Figure 6: Graphical (a) top view and (b) side view of the bydroponic model (Functional view).

\section{Fertigation}

For hydroponically grown plants, the nutrient solution used in this model is specifically formulated to satisfy their nutrient and mineral requirements. Three different types of fertilizers, called Flora Gro (For root strength), Flora Micro (Dilute for stem and plant growth), and Flora Bloom (Combo of nutrients needed at different growth stages), are used in the combination solution. The sum of these nutrients used as part of the nutrient solution at weekly intervals is illustrated in Table 3. Liquid fertilizer is discharged into the distilled water with the help of a syringe one by one, and the syringe is used to release a calculated amount of nutrients. It is crucial to dilute each fertilizer separately to ensure that nutrients do not bound by the reaction. Table 3 reveals that the usage of three kinds of liquid fertilizer is used weekly at various amounts, the variation in quantity is attributable to a particular variety of spinach keeping in mind its needs. Fertigation has been applied that can increase the growth and efficiency of every plant by adding a good volume of liquids, which can help in finding the effects of deficiency or excessive application of any specific nutrient in any plant.

\section{Table 3: Nutrient solution used in bydroponic model.}

\begin{tabular}{llllll} 
S. No & $\begin{array}{l}\text { Application } \\
\text { interval } \\
\text { (Weeks) }\end{array}$ & $\begin{array}{l}\text { Flora } \\
\text { micro } \\
(\mathbf{m l})\end{array}$ & $\begin{array}{l}\text { Flora gro } \\
(\mathbf{m l})\end{array}$ & $\begin{array}{l}\text { Flora } \\
\text { bloom } \\
(\mathbf{m l})\end{array}$ & $\begin{array}{l}\text { water } \\
\text { applied } \\
\text { (litre) }\end{array}$ \\
\hline 1 & $1^{\text {st }}$ & 10 & 10 & 5 & 8 \\
2 & $2^{\text {nd }}$ & 8 & 8 & 8 & 8 \\
3 & $3^{\text {rd }}$ & 8 & 2 & 10 & 8 \\
Total & 3 & 26 & 20 & 23 & 24
\end{tabular}

Table 4: Efficiency of Stock Solution under both replications.

\begin{tabular}{lllll} 
S. No & $\begin{array}{l}\text { Water } \\
\text { applied } \\
\text { (Liters) }\end{array}$ & Duration & \multicolumn{2}{c}{$\begin{array}{c}\text { Mixture uptake by plants } \\
\text { (Liters) }\end{array}$} \\
1 & 8 & $1^{\text {st } w e e k ~}$ & 0.932 & 0.937 \\
2 & 8 & $2^{\text {nd }}$ week & 0.847 & 0.839 \\
3 & 8 & $3^{\text {rd }}$ week & 0.7 & 0.706 \\
Total & 24 & 21-Days & 2.479 & 2.482 \\
Utilization (\%) & & 10.33 & 10.34 \\
Efficiency (\%) & & 89.67 & 89.66
\end{tabular}


Stock solution up-take

The quality of the stock solution defines how the plants under hydroponic production use the nutrientwater mixture. The overall stock solution performance of both replications was 89.66 percent, which means that 21.52 liters of a solution that could be used for further replications were saved. The total stock solution savings suggest that hydroponic cultivation does not result in any lack of water and nutrients. The quality of the stock solution (water-nutrient mixture) under both replications is explained in Table 4.

\section{Irrigation water up-take}

The irrigation was used for the observation of applied water loss. Irrigation was applied over three-day interval periods under conventional spinach crop cultivation. Table 5 indicates that during the entire experiment, a total of 96 liters of irrigation water was used for each plot (21 days). Also, the heavy usage of water is due to its loss below the root zone since soil only retains water up to its level of field potential, and plants can only soak up water from the root zone. Due to irrigation water loss, the nutrient extract is also lost. In terms of saving water and nutrients solutions, hydroponic cultivation is highly productive. The efficacy of Hydroponics was assessed by comparing the data of its stock solution shown in Table 3 against the use of irrigation water in geoponic (traditional) agriculture shown in Table 4 and Figure 7, respectively. In the hydroponic model, the volume of water applied, on average, 2.48 liters in 21 days, which is 97.42 percent fewer than that of the conventional system. Also, this high productivity of the hydroponic model indicates that liquid nutrients (fertilizer applied) can also be saved at high volumes.

\section{Stock solution properties}

The stock solution was prepared by combining 8 liters of treated (distilled) water with the nutrient solution combination at the rate indicated by General Hydroponics (Liquid fertilizer company). The specially formulated stock solution has an advantage over the conventional nutrient distribution method because nutrients or minerals in the traditional method need to be frequently distributed. The plants can use the stock solution for their healthy growth and production without draining it out of the tank. In contrast, the conventional approach still causes nutrient wastage due to drainage. A water nutrient mixture for hydroponic is required in its given limits. It is vital because if the electrical conductivity and total dissolved solids of water are not maintained, then the water would cross its permissible limit after introducing nutrients and affect plants' overall growth. Potential hydrogen also plays a role in the uptake of nutrients. Too high or low $\mathrm{pH}$ levels may prevent nutritional uptake and lead to deficiencies since each plant has its optimal $\mathrm{pH}$ range for the plant to take nutrients. For that, the values of EC, $\mathrm{pH}$, and TDS were checked at three days intervals for 21 days, which are shown in Table 6.

Table 5: Average irrigation volume applied under both replications of traditional cultivation of spinach crop.

$\begin{array}{lllll}\begin{array}{l}\text { S. } \\ \text { No }\end{array} & \begin{array}{l}\text { Ambient } \\ \text { tempera- } \\ \text { ture }\left({ }^{\circ} \mathbf{C}\right)\end{array} & \begin{array}{l}\text { Volume applied } \\ \text { plot 1 (Liters) }\end{array} & \begin{array}{l}\text { Volume applied } \\ \text { plot 2 (Liters) }\end{array} & \begin{array}{l}\text { Irrigation } \\ \text { interval } \\ \text { (Days) }\end{array} \\ 1 & 37.0 & 12 & 12 & 1^{\text {st }} \\ 2 & 33.0 & 12 & 12 & 3^{\text {rd }} \\ 3 & 34.0 & 12 & 12 & 6^{\text {th }} \\ 4 & 33.0 & 12 & 12 & 9^{\text {th }} \\ 5 & 31.0 & 12 & 12 & 12^{\text {th }} \\ 6 & 31.0 & 12 & 12 & 15^{\text {th }} \\ 7 & 29.5 & 12 & 12 & 18^{\text {th }} \\ 8 & 30.0 & 12 & 12 & 21^{\text {st }} \\ \text { Total } & 96 & 96 & 21 \text { Days }\end{array}$

Table 6: Stock solution chemical properties under both replications.

\begin{tabular}{|c|c|c|c|c|c|c|c|}
\hline & $\begin{array}{l}\mathrm{EC}(\mu \mathrm{S} / \\
\mathrm{cm})\end{array}$ & $\begin{array}{l}\text { TDS } \\
(\mathrm{ppm})\end{array}$ & $\mathrm{pH}$ & $\begin{array}{l}\mathrm{EC}(\mu \mathrm{S} / \\
\mathrm{cm})\end{array}$ & $\begin{array}{l}\text { TDS } \\
(\mathrm{ppm})\end{array}$ & $\mathbf{p H}$ & $\begin{array}{l}\text { Growth du- } \\
\text { ration (Days) }\end{array}$ \\
\hline & Reservoir & $r 1$ & & Reservo & & & \\
\hline 1 & 1508 & 754 & 5.6 & 1422 & 711 & 6.1 & $1^{\text {st }}$ \\
\hline 2 & 1950 & 975 & 6.4 & 1486 & 754 & 5.9 & $3^{\text {rd }}$ \\
\hline 3 & 1698 & 849 & 6.0 & 1756 & 878 & 5.7 & $6^{\text {th }}$ \\
\hline 4 & 1444 & 733 & 5.9 & 1360 & 690 & 6 & $9^{\text {th }}$ \\
\hline 05 & 1402 & 711 & 6.2 & 1292 & 646 & 5.1 & $12^{\text {th }}$ \\
\hline 6 & 1422 & 711 & 5.6 & 1508 & 754 & 6.8 & $15^{\text {th }}$ \\
\hline 7 & 1056 & 528 & 6.5 & 1078 & 539 & 6.4 & $18^{\text {th }}$ \\
\hline 8 & 1250 & 625 & 6.3 & 1219 & 608 & 6.5 & $21^{\mathrm{st}}$ \\
\hline
\end{tabular}

\section{Growth quality of spinach}

At the end of the experiment, the growth parameters of spinach plants (including height, stem size, and leaf area) and the appearance of color were evaluated. The growth output of spinach plants under both replications of the hydroponic technique is seen in Figures 7 and 8. The height of the plants ranged from $20.45 \mathrm{~cm}$ to $23.65 \mathrm{~cm}$, the Width of the stem ranged from $0.13 \mathrm{~cm}$ to $0.18 \mathrm{~cm}$, and the leaf area 
of the plants ranged from $1.19 \mathrm{~cm}^{2}$ to $2.27 \mathrm{~cm}^{2}$. On average, spinach height, stem size, and leaf area were $22 \mathrm{~cm}, 0.15 \mathrm{~cm}$, and $1.95 \mathrm{~cm}^{2}$. The dark green color of the spinach leaf reflects the high nature of the hydroponically handled spinach plant. The height of the plant under geoponic treatment was $16.59 \mathrm{~cm}$ on average. The mean size and leaf area of the stem were $0.12 \mathrm{~cm}$ and $1.50 \mathrm{~cm}^{2}$, respectively. Pale, yellow, and light green were the colors of the spinach leaves observed under the geoponic procedure. The pale color indicates that there is a lack of a chlorophyll system. In contrast, the yellow color indicates a deficit of potassium due to the loss of the root zone of waterfertilizer extract, or too little light is given from the atmosphere. Whereas there is no decline in minerals in Hydroponics, the growth parameters and consistency of the spinach crop grown under geoponic cultivation are illustrated in Figures 8 and 9.

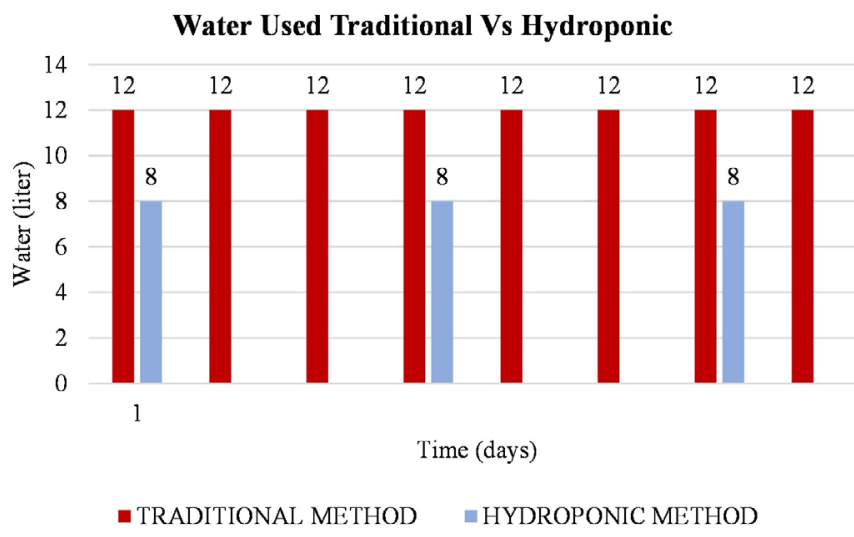

Figure 7: Water used hydroponic us traditional.

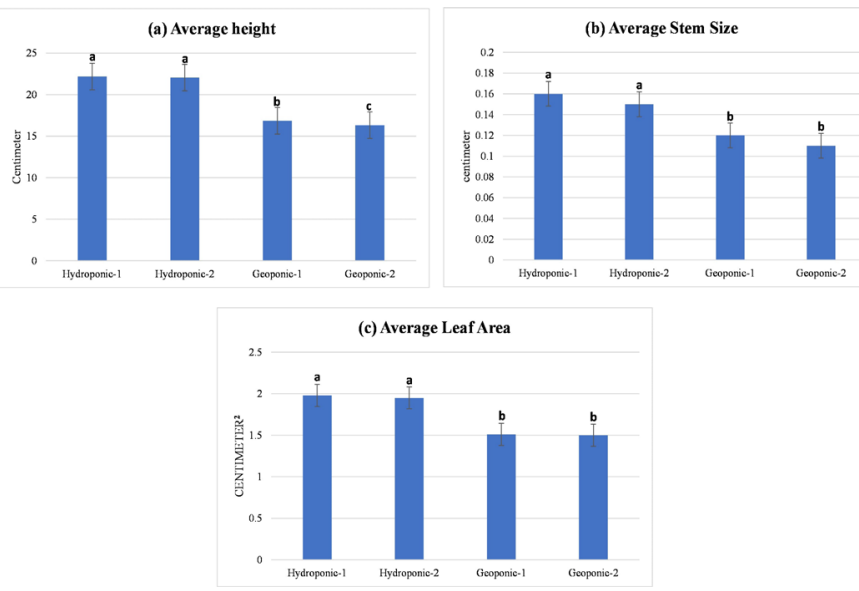

Figure 8: Average (a) Height (b) stem size and (c) Leaf area.

The present study was carried out to check the effectiveness of the hydroponic model for spinach crops and to compare its performance against conventional (geoponic) cultivation. The hydroponic version comprising of different components was manufactured, so. Even the water-nutrient extract saving outcomes with the study are greatly encouraged by Bradley and Marulanda (2001); Sheikh (2006), in which they stated hydroponic farming is obviously thought to be superior to geoponic (conventional) farming systems, particularly for water and nutrient utilization efficiencies. Grewal et al. (2011) reasoned that hydroponic farming approaches are best suited to recycle the minerals and water (nutrition) because as a result of ease in drainage capturing options for reuse. Hydroponic technology can considerably diminish the contamination of water-nutrient infusion. In contrast, backing to some reduction in water and fertilizer ingestion and the re-utilizing of this stock solution does not restrict crop yields. The consequences of the present study also resemble that the total saving of stock solution was $97.42 \%$ efficient, comparing in regards to geoponic cultivation. In contrast, the increase of the poultry plants was also superior to geoponic growth operations. The plant growth performance detected in this study is prominently supported by (Oztekin et al., 2018) in which they reasoned that the hydroponic farming technique has significant result over the spinach development parameters such as height, root length, leaf brand new dry matter contents, root dry weight, and dry weights. But under this analysis, the growth parameters such as height, stem size, and leaf area have been increased by 26 percent as compared to the conventional farming (Geoponic) method. Furthermore, they also reasoned that the concentration of nutrient therapy has prominently increased the growth performance of spinach crops. Concerning the quality progress and increase of return under hydroponic cultivation, the outcomes of the experiment revealed that the highquality assessment by the appearance of leaf color indicates that the spinach plants have satisfactorily absorbed the essential degree of the nutrient in-stock solution under deep water culture farming. However, the rich cultivated spinach caliber ensured that it is undoubted without nutrient absorption from spinach plants that impact the inadequate foliage growth, and also, the colors detected were light, yellow, and green. But under hydroponic farming that the leaf color was dark. These outcomes are in quite an agreement with the conclusions drawn by Carrasco et al. (2003) along with Cherif et al. (1997), by which they stated that hydroponic farming has significantly improved the chlorophyll system along with suitable nutrient supply method which led more return and superior quality compared to geoponic cultivation. The quality parameters may also be evaluated by the appearance of fruits and leaves. 


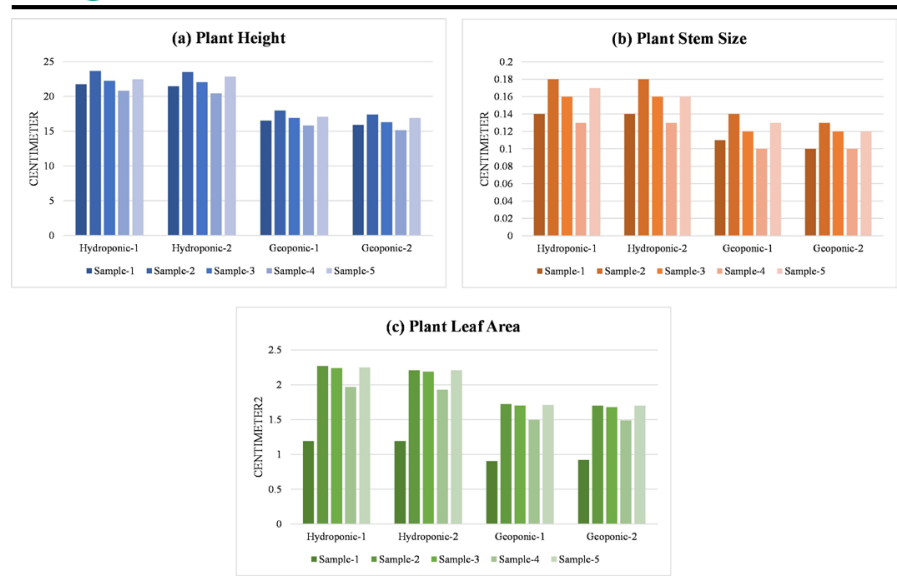

Figure 9: Plant (a) Height (b) stem size and (c) Leaf area.

\section{Conclusions and Recommendations}

The existing research has concluded that the soilless cultivation system allows environmental protection against non-reuse systems that degrade groundwater, soil, and other aspects of the environment. Hydroponics can therefore play a significant role in areas with soil and water constraints. The improved physical characteristics of spinach indicate an increased advantage of hydroponic technology that shows a better increase in spinach yield up to 26 percent in growth performance. Hydroponic technology was used to save high percentage amounts of water and fertilizer, comparable to surface (conventional) irrigation systems in terms of waternutrient solution saving ( $89.67 \%$ efficiency). It is crucial to develop low-cost hydroponic technologies that reduce reliance on human labor and lower overall start-up and operational costs to promote commercial hydroponic farming.

\section{Novelty Statement}

For the first time in Pakistan, we report that spinach growing can be done with higher productive and economic returns using a locally developed and assembled hydroponic (soilless) cultivation system.

\section{Author's Contribution}

Ain-ul-Abad Syed: Executed the experiment, lab analysis, data collection and overall paper writeup.

Zaheer Ahmed Khan: Conveyed the idea of the experiment with technical input at every step and paper write up.

Shakeel Hussain Chattha: Provided technical help during hydroponic design and fabrication.
Irfan Ahmed Shaikh: Helped in lab analysis and paper write up.

Mian Noor Hussain Asghar Ali: Helped with the write-up by data entry in SPSS and its analysis and providing technical input at each stage.

Zohaib ur Rehman Bughio: Provided technical help during soil experiment and helped in paper write up. Shahzad Hussain Dahri: Helped in overall management of the article.

Ghous Bakhsh Buriro: Helped in arrangement of hydroponic system and paper writeup.

\section{Conflict of interest}

The authors have declared no conflict of interest.

\section{References}

Ako, H. and A. Baker. 2009. Small-scale lettuce production with hydroponics or aquaponics. Sustain. Agric., SA-2: 1-7.

Arifullah, S.A., A.F. Chishti, M. Zulfiqar, G. Yasmeen, N. Farid and I. Ahmad. 2009. Estimating yield potential of the major crops and its implications for Pakistan's crops sector. 25: 611-615.

Bhatti, S.M., A.K. Gadehi, I. Rajpar, M.N. Kandhro, M.K. Soothar and Z.U.R. Bughio. 2021. Effect of saline water on growth, yield and ions content in spinach genotypes. J. Innov. Sci., 7: 78-87. https://doi.org/10.17582/journal. jis/2021/7.1.78.87

Biemond, H., J. Vos and P.C. Struik. 1996. Effects of nitrogen on accumulation and partitioning of dry matter and nitrogen of vegetables. 3 . Spinach. Netherlands J. Agric. Sci., 44: 227239. https://doi.org/10.18174/njas.v44i3.547

Bradley, P.M.C., 2001. Simplified hydroponics to reduce global hunger. Acta Hortic., 554, ISHS 2001, 24: 289-295. https://doi.org/10.17660/ ActaHortic.2001.554.31

Carrasco, G., A.C. Martínez, O. Márquez, D. Osorio, M. Urrestarazu and M.C. Salas. 2003. Vegetable seedlings grown in a float system. Acta Hortic., 614: 241-245. https://doi. org/10.17660/ActaHortic.2003.614.35

Cherif, M., Y. Tirilly and R.R. Bélanger. 1997. Effect of oxygen concentration on plant growth, lipidperoxidation, and receptivity of tomato roots to Pythium $\mathrm{F}$ under hydroponic conditions. Eur. J. Plant Pathol., 103: 255-264. https://doi.org/10.1023/A:1008691226213 
Domingues, D.S., H.W.Takahashi, C.A.P. Camara and S.L. Nixdorf. 2012. Automated system developed to control $\mathrm{pH}$ and concentration of nutrient solution evaluated in hydroponic lettuce production. Comput. Electron. Agric., 84: 53-61. https://doi.org/10.1016/j. compag.2012.02.006

Ferreira,J.F.S.,D. Sandhu,X. Liu and J.J.Halvorson. 2018. Spinach (Spinacea oleracea L.) response to salinity: Nutritional value, physiological parameters, antioxidant capacity, and gene expression. Agriculture, 8: 1-16. https://doi. org/10.3390/agriculture8100163

Government of Pakistan 2019. Agriculture Finance Survey sof Pakistan 2017-18. Minist. Finance GoP.

Government of Pakistan 2014. Agriculture Statistics of Pakistan 2012-13. Minist. Food Secur. Res. GoP.

Grewal, H.S., B. Maheshwari and S.E. Parks. 2011. Water and nutrient use efficiency of a low-cost hydroponic greenhouse for a cucumber crop: An Australian case study. Agric. Water Manage., 98: 841-846. https://doi.org/10.1016/j. agwat.2010.12.010

Gruda, N., 2009. Do soilless culture systems have an influence on product quality of vegetables? J. Appl. Bot. Food Qual., 82: 141-147.

Hawkes, L. (2014). Ogallala Aquifer levels dropping faster than expected. Retrieved 3 20, 2015, from Southwest Farm Press: https://www. farmprogress.com/water-shortage/ogallalaaquifer-levels-dropping faster-expected

Huttner, D. and D. Bar-zvi. 2003. An improved, simple, hydroponic method for growing Arabidopsis thaliana. Plant Mol. Biol. Rep., 21: 59-63. https://doi.org/10.1007/BF02773397

Janeczko, D.B. and M.B. Timmons. 2019. Effects of seeding pattern and cultivar on productivity of baby spinach (Spinacia oleracea) grown hydroponically in deep-water culture. Horticulturae, 5:1-12.https://doi.org/10.3390/ horticulturae 5010020

Jovicich, E., D.J. Cantliffe and P.J. Stoffella. 2003. Spanish pepper trellis system and high plant density can increase fruit yield, fruit quality, and reduce labor in a hydroponic, passive-ventilated greenhouse.Acta Hortic., 614:255-262.https:// doi.org/10.17660/ActaHortic.2003.614.37

Khan, S., R. Tariq, C. Yuanlai and J. Blackwell. 2006. Can irrigation be sustainable? Agric. Water
Manage., 80: 87-99. https://doi.org/10.1016/j. agwat.2005.07.006

Malik, A.M., K.M. Mughal, S.A. Mian and A.U. Khan. 2018. Hydroponic tomato production and productivity improvement in Pakistan. Pak. J. Agric. Res., 31: 133-144. https://doi. org/10.17582/journal.pjar/2018/31.2.133.144

Maneejantra, N., S. Tsukagoshi and N. Lu. 2016. A quantitative analysis of nutrient requirements for hydroponic spinach (Spinacia oleracea L.) production under artificial light in a plant factory. J. Fertil. Pestic., 7: 2-5. https://doi. org/10.4172/2471-2728.1000170

Manzocco, L., M. Foschia, N. Tomasi, M. Maifreni, L.D. Costa, M. Marino, G. Cortella and S. Cesco. 2011. Influence of hydroponic and soil cultivation on quality and shelf life of ready-toeat lamb's lettuce (Valerianella locusta L. Laterr). J. Sci. Food Agric., 91: 1373-1380. https://doi. org/10.1002/jsfa.4313

Ministry of National Food Security and Research 2012. Draft Agriculture and Food Security policy of Pakistan. Minist. National Food Secur. Res. GoP.

Muchate, N.S., N.S. Rajurkar, P. Suprasanna and T.D. Nikam. 2019. $\mathrm{NaCl}$ induced salt adaptive changes and enhanced accumulation of 20-hydroxyecdysone in the in vitro shoot cultures of Spinacia oleracea (L.). Sci. Rep., 9: 1-11. https://doi.org/10.1038/s41598-01948737-6

Nicola, S., J. Hoeberechts and E. Fontana. 2007. $\mathrm{Ebb}$ and flow and floating systems to grow leafy vegetables: A review for rocket, corn salad, garden cress and purslane. Acta Hortic., 747: 585-592. https://doi.org/10.17660/ ActaHortic.2007.747.76

Oulai, P., L. Zoue, R-M. Megnanou, R. Doue and S. Niamke. 2014. Proximate composition and nutritive value of leafy vegetables consumed in northern Côte D' Ivoire. Eur. Sci. J., 10: 212227.

Oztekin, G.B., T. Uludağ and Y. Tüzel. 2018. Growing spinach (Spinacia oleracea L.) in a floating system with different concentrations of nutrient solution. Appl. Ecol. Environ. Res., 16: 3333-3350. https://doi.org/10.15666/ aeer/1603_33333350

Polycarpou, P., D. Neokleous, D. Chimonidou and I. Papadopoulos. 2005. A closed system for soil less culture adapted to the cyprus conditions. 
Non-Convent. Water Use, 241: 237-241.

Resh, H.M., 2013. A definitive guidebook for the advanced home gardener and the commercial hydroponic grower.

Sheikh, B.A., 2006. Hydroponics: Key to sustain agriculture in water stressed and urban environment. Pak. J. Agric. Agric. Eng. Vet. Sci., 22: 53-57.

Steyn, N.P., J. Olivier, P. Winter, S. Burger and C. Nesamvuni. 2001. A survey of wild, green, leafy vegetables and their potential in combating micronutrient deficiencies in rural populations. S. Afr. J. Sci., 97: 276-278.

Suhardiyanto, H., C. Arif and B.I. Setiawan. 2009. Optimization of EC values of nutrient solution for tomato fruits quality in hydroponics system using artificial neural network and genetic algorithms. ITB J. Sci., 41: 38-49. https://doi. org/10.5614/itbj.sci.2009.41.1.3

Suyantohadi, A., T. Kyoren, M. Hariadi, M.H. Purnomo and T. Morimoto. 2010. Effect of high consentrated dissolved oxygen on the plant growth in a deep hydroponic culture under a low temperature. IFAC Proc., Vol. 3. https:// doi.org/10.3182/20101206-3-JP-3009.00044

Szilágyi, Z., K. Slezák, A. Ferenczy and I. Terbe.
2006. Hydroponic pepper growing on baked clay pellets. Int. J. Hortic. Sci., 12: 37-40. https://doi.org/10.31421/IJHS/12/4/676

Trimble, S. 2019. Blog: Leaf Area - How \&amp; Why Measuring Leaf Area is Vital to Plant Research. Retrieved October 27, 2020, from https://cid-inc.com/blog/leaf-area-how-whymeasuring leaf-area-is-vital-to-plant-research/

United Nation. 2014. United Nation department of Economic and Social Affairs, Population Division,

Population Estimates and Projection Section. http://esa.un.org/wpp/Excel-Data/population. html

Wang, Y.L., Wang, G.X., Yan, Y., 2013. Scientific research project cost estimating method and system based on improved BP neural network. Adv. Mater. Res. 756-759, 1696-1700. https://doi.org/10.4028/www.scientific.net/ AMR.756-759.1696

Waqas, A., M. Umair, R.N. Ahmad, Zia-ulHaq and K.S. Khan. 2021. Assessment of crop responses and climatic parameters by developing indigenous hydroponic greenhouses in different regions of Punjab-Pakistan. Pak. J. Agric. Sci., 58: 643-654. 